bringing the said Brorsen's comet into line with most other comets, as to possessing both that band and material.

Secondly, Dr. Watts alludes to Mr. Christie, of the Royal Observatory, Greenwich, having also recently observed the spectrum of the same comet, and stated that he had thereoy found the same result as Prof. Young. But the Doctor implies there must be some mistake therein, because--what Mr. Christie compared the sharp edge of the comet's green band, with, and found it coincident, was not the Bunsen gas burner's green band, but that of an alcohol vacuum tube illumined by electric spark; and this latter green band, he says, is in an absolutely different spectrumplace to that occupied by the coal-gas burner's green band.

The first answer here, is both pleasant and simple. I know perfectly well what it is the Doctor alludes to, as being visible in tie alcohol vacuum tube, but would beg to remind an accom. plished laboratory worker that it is so close in spectral place to the coal-gas flame's green band, that in any spectroscope of very small dispersion, and when the subject is seen only faintly and at intervals in a difficult astronomical observation, such minute difference of place might well be disregarded in comparison with the enormous difference or anomaly of an older, almost historic, record, whose large discrepance, eight times larger than the other difference, was really the thing which both Mr. Christie and Prof. Young had before them, either to prove or disprove. And as they have now each of them independently assured us, by special observations at the end of a telescope in the cold night air, that the enormous anomaly suspected of old no longer exists-they both deserve our best thanks.

But next comes, for those who work in-doors with brighter lights and more powerful spectroscopes, the second part of the answer, with a proof that $\mathrm{Mr}$. Christie, after all, may not have nsed a differently placed reference to Prof. Young's, even in the least degree, because, besides what Dr. Marshall Watts says very truly, there is in the spectrum of an alcohol vacuum tube electrically illumined, there is also a something else which he either has not seen, or has not yet recognised as such, but which is the very identical green band of the coal-gas flame in open air.

The special green band which the Doctor has seen and recognised in an alcohol vacuum tube is to be seen equally in vacuum tubes of all gases containing carbon in any combination, and is therefore abundantly visible in tubes of carbon monoxide, carbon dioxide, and cyanogen. This, too, is the spectrum which he calls the "Carbon spectrum No. 2," but which I call simply the spectrum of carbon; a spectrum which no one has yet found in any common candle flame, coal-gas flame, or comet in the sky; and it requires apparently the ecstatic heating of the electric spark for its smallest development.

But the other green band, which I shall presently prove is also in an alcohol vacuum tube, though the Doctor may not have recognised it there, he has seen abundantly elsewhere, for it is found in the blue base of every candle, lamp, or coal-gas flame and he has given the spectrum place of the beginning of it with exceeding accuracy. In fact, the only unhappy thing is, that he will look upon it as pure carbon, calling it the "Carbon spectrum No. I," when it is so evidently the compound "carbo. hydrogen ;" for with my new end-on tubes, while I do not see this green band in vacua of either carbo-oxygen or carbo-nitrogen (unless ultra-faintly as a trace of impurity), I do see it, and most brilliantly, in tubes of such rich carbo-hydrogens as alcohol and olefiant gas.

Now it is not a little singular as a coincidence merely, that I was actually engaged only yesterday, after an interval of severa years, in pointing out to my friend Prof. Swan, of St. Andrews, the existence of "his" carbo-hydrogen blow-pipe flame's lines of its green band, projected upon, and differently placed from, the true elemental carbon green band of an alcohol vacuum tube, electrically illumined; and we proceeded thus to test the identity of what $I$ called "his" flame lines, by a close proof of place, which is everything in spectroscopy.

A coal-gas and air blow-pipe flame, end-on, was set up before the spectroscope on one side of the table, and on the other side an alcohol vacuum tube, illuminated by I-inch sparks from a small coil, and viewed also end-on. The spectroscope could be rotated easily in azimuth by endless screw motion, so as to look with its gathering telescope "first into the tube, then into the flame, and then again into the tube. The prism train had the large dispersion of $33^{\circ}$ :between $\mathrm{A}$ and $\mathrm{H}$, the telescope a mag. nifying power of 10, and its pointer was one of Mr. Hilger's latest and most refined steel wedges of almost infinite sharpness.
The slit was made exceedingly narrow, the definition in the centre of the field was super-excellent, and then Prof. Swan micrometrically bisected a certain thin but exceedingly brioht line, which looked like an anomaly on the surface, and far within the least refracted edge of the elemental carbon green band of the alcohol tube, and clamped the pointer in that exact spectrum place.

I then rotated the whole instrument round to the blow-pipe flame, and asked him "What is the pointer on now?"

"On the first and brightest line of the blow-pipe flame's green band," he answered, "Alexander 'Herschel's green giant of carbo-hydrogen, and it is admirably bisected too."

We next rotated back to the alcohol tube, and found the pointer still accurately bisecting that bright line present there, which was a total anomaly in a pure carbon spectrum, though perfectly agreeable to what Prof. Swan wrote of the compound carbo-hydrogen's flame spectrum, twenty-three years ago. Most opportunely present also in that tube, for it enabled Mr. Christie to compare Brorsen's comet with the same identical reference as that used by Prof. Young, though employing an alcohol spark spectrum, and not a gas-burner.

The second line of the blow-pipe flame's green band, though much fainter, is also distinctly seen in the end-on view of the alcohol tube's spectrum, and answers perfectly to a similar test for place as the first line. Wherefore, I would beg to ask, how can I hold any other view than that carbon, as a pure chemical element, and the most refractory that is known, has no spectrum short of electric spark temperature; and what it then shows is, to exact measurement with large dispersion, a perfectly different spectrum to that of the compound gas, carbo-hydrogen; which compound gas, while still existing to some extent. in 'the electric spark tubes, begins its spectral manifestations in the very moderate temperature of merely a farthing tallow candle : a matter to be duly considered in studying the physical condition of comets, which do not show any spectrum (or, for small and "uncondensed " sparks, we may say the spectrum) of pure elemental carbon.

Edinburgh, May 9 Piazzi SMYTH

\section{The Victoria University}

In the article on the Victoria University in the last number of NATURE, I observe some inaccurate statements regarding the Queen's University in Ireland.

In the first place there are not four colleges, but three. Next there are no degree examinations in any college, but all are conducted in Dublin by the examiners of the university, who, for the most part, are also professors in the colleges; but there are some examiners who are not professors, and also some professors who are not examiners.

Peterhouse, Cambridge

Maps of Old Geological Coast-lines, \&c., \&c.

I Notice in Woodward's "Manual of the Mollusca," when spealsing of the "Boundaries of Natural History Provinces," p. 352 , the following:-

"The seas are divided by continents and influenced by the physical character of coast-lines, by climates, and currents."

May not the occurrence of different species in different parts of contemporaneous strata help to determine the positions of land and water, \&c., in past geological ages?

Cambridge

[In reply to "W. W.'s" interrogatory, "May not the occurrence of different species in different parts of contemporaneous strata help to determine the positions of land and water, \&c., in past geological ages?" we would say, Yes, most certainly; and it is not only by recording the occurrence of different species, probably peculiar to different zones of depth, that geologists have long tried to mark out old sea-beds, but more especially by tracing carefully the occurrence of the same species along ex. tended lines of formations, they have attempted to map out old geological coast-lines. Much has been done in this direction by Godwin-Austen, Forbes, Quenstedt, Oppel, Waagen, Hebert, Oswald Heer, and many others; but much more remains to be accomplished, and "W. W." cannot do better than take up some such line of inquiry for his summer vacations. How much good field-work might be done in three months' holidays in, say, three successive years, with a knapsack on one's back and a hammer in one's hand, let the admirable papers by Dr. Chas, Barrois of Lille tell! $-\mathrm{H}$. W.] 